\title{
ON CARDIOGRAPHY,
}

WITH SPECIAL RBFERENCE TO THE

RELATION OF THE TIME OF DURATION OF VENTRICULAR SYSTOLE TO THAT OF DIASTOLIC INTERVAL.

BY

PAUL M. CHAPMAN, M.D.LoNd., M.R.C.P., PHYGICIAN TO THE HEREFORD GENGRAL INEIRMARY.

Received November 10th, 1885-Read March 9th, 1886.

THE object of the present paper is to bring forward the subject of cardiography, with special reference to the relation of the time of duration of ventricular systole to the time of diastolic interval ; to give a short account of some former work in this direction; and to make public so much of the present state of the subject as is due to my own observations. It may also create an interest in the matter which may lead to good results in the future. At the present moment I believe that I am, most unfortunately, the only physician in this country who habitually uses the cardiograph clinically; I myself have only been able to employ it with advantage since I have established a certain basis of comparison to work by. These preliminary experiments and observations having been made, the cardiograph should now come into ordinary use in medicine, and not remain solely an item of the physiological laboratory. 
The particular instrument by means of which my observations have been made, and one which is capable of producing very beautiful tracings, is that of Marey as modified by Dr. Burdon-Sanderson; an air-tight tympanum, shaped- like a kettledrum in miniature, from the moveable surface of which projects a button which is adjusted to the point of maximum impulse of the heart. The interior of the tympanum is connected by means of a piece of elastic tubing with a second tympanum, to which is attached a lever which marks on a revolving drum tracings of the impulses transmitted from the apex of the heart by means of the cardiograph.

The time occupied by a single revolution of the drum being known, the duration of time occupied in the production of any part of the tracing may of course be measured, by means of ordinates curved according to the length of the lever, which is the radius of the curve. The time occupied in the production of any part of the tracing may be measured quite easily to the 200th part of a second.

1.

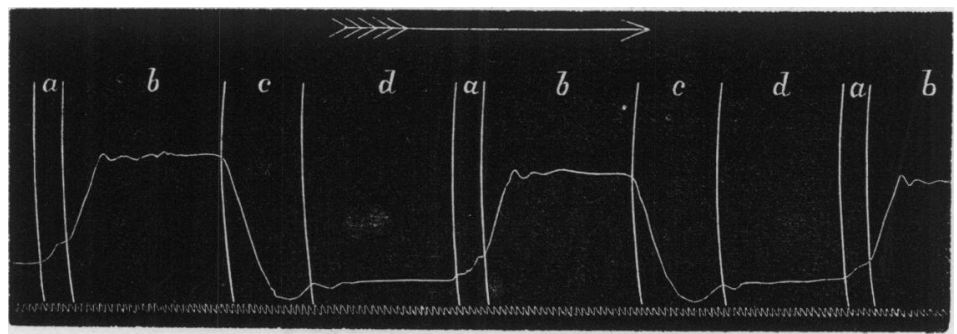

a. Auricular systole. b. Ventricular systole. c. Cessation of ventricular contraction and fall of lever. $d$. Gradual filling of ventricle previous to auricular contraction.

In Fig. 1 a normal tracing is given. I may incidentally mention, in order to show how easily tracings may be taken with practice, that it is an exact copy of one taken by myself from my own heart, without assistance in managing the apparatus. The whole cardiac 
revolution occupies $\cdot 9230^{\prime \prime}$, of which the ventricular systole occupies $\cdot 3260^{\prime \prime}$ and the diastole $\cdot 5970^{\prime \prime}$. The pulserate is 65 per minute; the auricular systole occupies -0650", about one fifth of the ventricular systole.

Experiments were made, to determine the duration of the various parts of the heart revolutions, by Dr. Landois, and published by him ten years ago. ${ }^{1}$ Dr. Landois made out an elaborate table of measurements for a single heart revolution at a pulse-rate of 55 per minute. Briefly, his duration of ventricular systole is $\cdot 346^{\prime \prime}$, corresponding almost absolutely to my own measurement of ' $343^{\prime \prime}$; but he places the duration of auricular systole at $\cdot 170^{\prime \prime}$, which, according to my own experiments, is too long, as I have not found it to exceed $100^{\prime \prime}$, while it is usually less.

Dr. Landois does not attempt to determine the duration of ventricular systole at different pulse frequencies. Any experimenter would soon find that the duration of ventricular systole declines with any increase of frequency of the pulse, and it becomes obvious that, before it would be possible to use the cardiograph for clinical purposes, and to estimate any alterations in disease, it would be necessary to make out by what regular manner, if any, the duration of ventricular systole declines.

It will be within the memory of many that details of experiments were published in the year 1871 by Dr. A. H. Garrod ${ }^{2}$ to establish the duration of ventricular systole for different rapidities of pulse. His experiments were made with the earlier instruments of Marey. It is incumbent on me to criticise his results as I have found them to be valueless. The very tracings he published are not in my estimation satisfactory; and the mathematical formula given by him for determining the duration of ventricular systole at any given pulse frequency is not only vexatiously troublesome to use, but is based on

1 'Graphische Untersuchungen über den Herzschlag,' Berlin, 1876.

2 'Journal of Anat. and Phys.,' vol. v [second series, vol. iv], pp. 17-27. 
incorrect observations, and necessarily furnishes incorrect results.

Dr. Garrod's statement, in his own words, is this :"On comparing traces of different rapidities, it was found that the length of the first part varied very definitely, inversely as the rate; not so quickly; but as its square root; and the number of measurements that have been made seems to justify the law that, in health, the length of the first part of the heart's beat varies, for a given position of the subject, inversely as the square root of the rapidity."

Further, in a paper" on the "Mutual Relations of the Apex Cardiograph and the Radial Sphygmographic Trace," Dr. Garrod makes the following statement:"The first cardiac interval is that which occurs between the commencement of the systolic rise and the point of closure of the aortic valve, in cardiograph traces. The number of times that this interval is contained in its component beat is represented by $y$. The law as to its length may be stated thus : $x y=20 \sqrt{x}$, , $x$ representing the frequency of beat per minute.

The calculation of the length of the systole for any given pulse-rate by means of this very cumbrous formula could scarcely be tolerated were the result correct, as it involves several separate calculations. If, when the sum is worked out, we find the result is not in accordance with measurements obtained by experiment, the whole formula may be dismissed with a sense of relief. I should, how: ever, before doing so, justify myself by furnishing some calculations published in Dr. Garrod's paper ('Proceedings of the Royal Society ') :

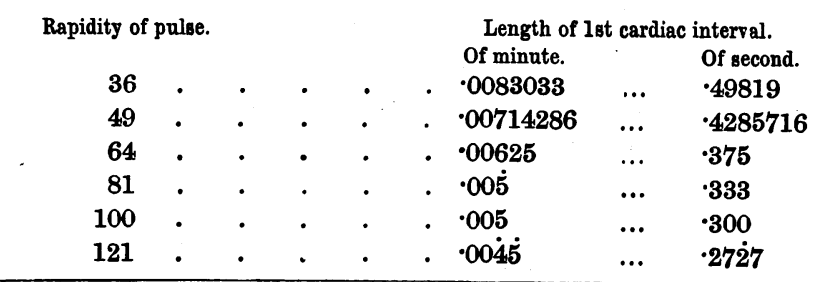

1 'Proceedings of the Royal Society,' Feb. 23rd, 1871. 
Following his formula, I have calculated out what would be, according to Dr. Garrod, the duration of systole in parts of a second, for every 10 beats increase of frequency per minute from 50 to 130 .

\begin{tabular}{|c|c|c|c|c|}
\hline \multicolumn{2}{|c|}{ Pulse-rate 50} & & \multicolumn{2}{|c|}{ Duration of systole $4244^{\prime \prime}$} \\
\hline " & 60 & $\ldots$ & , & $\cdot 384^{\prime \prime}$ \\
\hline " & 70 & $\ldots$ & " & -357" \\
\hline " & 80 & $\ldots$ & $"$ & $\cdot 333^{\prime \prime}$ \\
\hline , & 90 & ... & , & $\cdot 317^{\prime \prime}$ \\
\hline$"$ & 100 & ... & $"$ & $\cdot 300^{\prime \prime}$ \\
\hline , & 110 & $\ldots$ & 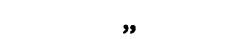 & $\cdot 287 "$ \\
\hline " & 120 & $\ldots$ & " & $\cdot 273^{\prime \prime}$ \\
\hline " & 130 & $\ldots$ & ", & $\cdot 263^{\prime \prime}$ \\
\hline
\end{tabular}

My own table is the result of experiments conducted on upwards of 150 different healthy people, all recumbent. Many of these, again, were caused to vary the pulse-rate by means of exercise, or a bath (the latter leading to various fallacies), or were observed under excitement which quickened the pulse. This table, which has been indispensable to me, and will be so, I hope, to others whom I trust I may attract into this field of investigation, is based upon no theory, but is entirely the result of experiment. Before giving it, I must state, and emphasize the fact, that variations from it are constantly noticed in healthy people, and even in the same person under different conditions, and that these variations may take place within a limit of $\cdot 02^{\prime \prime}$ either above or below the measurement given, though I consider this to be the maximum variation in health. I may with confidence and safety state that any variation exceeding this limit may justly be put down as abnormal, and that for high pulse-rates I do not allow a maximum of '02" above the duration of systole set forth in the table. The maximum is usually obtained with the lower pulse-rates, and I do not allow that for a low pulse-rate it should be less than what $I$ have given in my table. 
Table of duration of ventricular systole and of diastole (including auricular systole) of heart, for different rates of pulse.

\begin{tabular}{|c|c|c|c|c|c|c|}
\hline $\begin{array}{l}\text { Pulse-rate } \\
\quad \mathbf{4 5}\end{array}$ & $\ldots$ & $\begin{array}{l}\text { Systole. } \\
\text {.3600" }\end{array}$ & $\ldots$ & $\begin{array}{l}\text { Diastole. } \\
\text {.9733" }\end{array}$ & $\ldots$ & $\begin{array}{c}\text { Total. } \\
\cdot \mathbf{1} \cdot \mathbf{3 3 3 3 ^ { \prime \prime }}\end{array}$ \\
\hline 50 & $\ldots$ & .3515" & $\ldots$ & $\cdot 8485^{\prime \prime}$ & $\ldots$ & $1 \cdot 2000^{\prime \prime}$ \\
\hline 55 & $\ldots$ & $\cdot 3430^{\prime \prime}$ & $\ldots$ & $\cdot 7479^{\prime \prime}$ & $\ldots$ & $1 \cdot 0909^{\prime \prime}$ \\
\hline 60 & $\ldots$ & •3345" & $\ldots$ & $\cdot 6655^{\prime \prime}$ & $\ldots$ & $1 \cdot 0000^{\prime \prime}$ \\
\hline 65 & $\ldots$ & $\cdot 3260^{\prime \prime}$ & ... & $\cdot 5970^{\prime \prime}$ & $\ldots$ & $.9230^{\prime \prime}$ \\
\hline 70 & ... & .3175" & $\ldots$ & $\cdot 5395^{\prime \prime}$ & $\ldots$ & $.8570^{\prime \prime}$ \\
\hline 75 & ... & $\cdot 3090^{\prime \prime}$ & $\ldots$ & $\cdot 4910^{\prime \prime}$ & $\ldots$ & $8000^{\prime \prime}$ \\
\hline 80 & $\ldots$ & $\cdot 3005^{\prime \prime}$ & $\ldots$ & $\cdot 4495 "$ & $\ldots$ & $\cdot 7500^{\prime \prime}$ \\
\hline 85 & $\ldots$ & $\cdot 2920^{\prime \prime}$ & $\ldots$ & $\cdot 4140^{\prime \prime}$ & $\ldots$ & $\cdot 7060^{\prime \prime}$ \\
\hline 90 & $\ldots$ & •2835" & $\ldots$ & $\cdot 3831^{\prime \prime}$ & $\ldots$ & $\cdot 666 \dot{6}^{\prime \prime}$ \\
\hline 95 & ... & $\cdot 2750^{\prime \prime}$ & $\ldots$ & $\cdot 3566^{\prime \prime}$ & $\ldots$ & $\cdot 6316^{\prime \prime}$ \\
\hline 100 & $\ldots$ & $\cdot 2665^{\prime \prime}$ & $\ldots$ & $\cdot 3335 "$ & $\ldots$ & $\cdot 6000^{\prime \prime}$ \\
\hline 105 & $\ldots$ & $\cdot 2580^{\prime \prime}$ & $\cdots$ & $\cdot 3121^{\prime \prime}$ & $\ldots$ & $.5701^{\prime \prime}$ \\
\hline 110 & $\ldots$ & $\cdot 2495^{\prime \prime}$ & $\ldots$ & $\cdot 2959^{\prime \prime}$ & $\ldots$ & 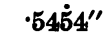 \\
\hline 115 & $\ldots$ & $\cdot 2410^{\prime \prime}$ & $\ldots$ & $\cdot 2807 "$ & $\ldots$ & $\cdot 5217^{\prime \prime}$ \\
\hline 120 & ... & $.2325 "$ & ... & $\cdot 2675^{\prime \prime}$ & $\ldots$ & $\cdot 5000^{\prime \prime}$ \\
\hline 125 & $\ldots$ & $\cdot 2240^{\prime \prime}$ & $\ldots$ & $\cdot 2560^{\prime \prime}$ & $\ldots$ & $\cdot 4800^{\prime \prime}$ \\
\hline 130 & ... & $\cdot 2155^{\prime \prime}$ & $\ldots$ & $\cdot 2460^{\prime \prime}$ & $\ldots$ & •4615" \\
\hline 135 & $\ldots$ & $\cdot 2070^{\prime \prime}$ & $\ldots$ & $\cdot 2374 "$ & $\ldots$ & $\cdot 4444^{\prime \prime}$ \\
\hline 140 & ... & $\cdot 1985^{\prime \prime}$ & ... & $\cdot 2301^{\prime \prime}$ & $\ldots$ & $\cdot 4286^{\prime \prime}$ \\
\hline 145 & ... & $\cdot 1900^{\prime \prime}$ & $\ldots$ & $\cdot 2238^{\prime \prime}$ & $\ldots$ & $\cdot 4138^{\prime \prime}$ \\
\hline 150 & $\ldots$ & $\cdot 1815^{\prime \prime}$ & $\ldots$ & $\cdot 2185^{\prime \prime}$ & $\ldots$ & $\cdot 4000^{\prime \prime}$ \\
\hline
\end{tabular}

The table represents, in decimal parts of a second, the time occupied by systole, or by diastole, of the heart in health for every increase in frequency of 5 beats per minute between 45 and 150 . It will be observed that, for every 5 beats increase in frequency per minute, there is a constant decrement in the duration of ventricular systole of '0085", my measurement of the duration of ventricular systole at a pulse-rate of 55 , viz. $\cdot 3430^{\prime \prime}$, almost exactly corresponding with that of Dr. Landois, which was $\cdot 3460^{\prime \prime}$.

Though my measurements do not agree with those of Dr. Garrod between 80 and 100, yet I should notice that the decrement between 80 and 100 is the same in both cases. 
I must point out certain facts which can be calculated from this table, and which bring to light very forcibly the importance of the diminution of the time of persistence in contraction of the ventricle being a regular and constant quantity. It should be well understood by every physician, that the fact that the time occupied by the ventricular systole diminishes by a constant quantity with increased rapidity of pulse, is one of the greatest importance to the welfare of the economy. By means of the table the time daily spent in work by the heart, and the period of rest which it enjoys will be for the first time made manifest ; the amount of work done being to a great extent a separate question, but being also to a great extent connected with the time expended in labour.

By multiplying the duration of systole for one cardiac revolution by the pulse-rate we get the time the ventricle expends in contraction per minute. At 75 the expenditure is $23 \cdot 175^{\prime \prime}$ in the minute, at 80 it is $24 \cdot 040^{\prime \prime}$. Thus, for an increased pulse frequency of 5 in the minute, between the pulse-rates of 80 and 85 , we find there is an increase in the time expended in contractions per minute of $\cdot 865^{\prime \prime}$, or nearly one second.

Now, at a pulse-rate of 120 the duration of ventricular systole is $2325^{\prime \prime}$; the time expended in ventricular contraction per minute being $27 \cdot 90^{\prime \prime}$. At a pulse-rate of 125 the duration of ventricular systole is $2240^{\prime \prime}$, with an expenditure of time in contraction per minute of $28^{\circ} 00^{\prime \prime}$. That is to say, for an increased pulse frequency of 5 in the minute, between 120 and 125, there is an increase in the time expended in contraction per minute of $\cdot 1^{\prime \prime}$, or only one tenth of a second.

Thus, owing to the constancy of the decrement in the duration of each systole as the cardiac revolutions increase in frequency per minute, we find that the total duration of contraction in the minute is increased but very slightly when we pass from one high pulse-rate to another still higher.

By this provision the whole period of diastole or of 
rest in health, is never diminished to less than half of the twenty-four hours. At a pulse-rate of 130, the period of rest is twelve and three quarter hours out of the twentyfour. The period of ventricular labour in health, therefore, never reaches half the day.

I have prepared a table in which the periods of labour and of rest of the ventricles during twenty-four hours are set forth for easy reference. It will be observed that, as the pulse-rate increases, and the need of rest grows more urgent, the period of rest lessens less rapidly ; and that, after a pulse-rate of 130 is reached, the period of diastole, or of rest, actually increases.

Time occupied in systole or diastole of ventricle during

\begin{tabular}{|c|c|c|c|c|}
\hline $\begin{array}{c}\text { Pulse-rate. } \\
45\end{array}$ & $\ldots$ & $\begin{array}{l}\text { Diastole. } \\
17^{\mathrm{h}} 12^{\prime}\end{array}$ & $\ldots$ & $\begin{array}{l}\text { Systole } \\
6^{\mathbf{h} 48^{\prime}}\end{array}$ \\
\hline 50 & $\ldots$ & $16^{\mathrm{h}} 54^{\prime}$ & $\ldots$ & $7^{h} 6^{\prime}$ \\
\hline 55 & $\ldots$ & $16^{\mathrm{h}} 24^{\prime}$ & $\ldots$ & $7^{\text {hb }} 6^{\prime}$ \\
\hline 60 & $\ldots$ & $16^{\mathrm{h}} \sigma^{\prime}$ & $\ldots$ & $8^{\text {h }} 0^{\prime}$ \\
\hline 65 & $\ldots$ & $15^{\mathrm{h}} 31^{\prime}$ & $\ldots$ & $8^{\mathrm{h}} 29^{\prime}$ \\
\hline 70 & $\ldots$ & $15^{\mathrm{b}} 5^{\prime}$ & $\ldots$ & $8^{\text {h } 55^{\prime}}$ \\
\hline 75 & ... & $14^{\mathrm{h}} 43^{\prime}$ & $\ldots$ & $9^{\mathrm{h}} 17^{\prime}$ \\
\hline 80 & ... & $14^{\mathrm{h}} 24^{\prime}$ & $\ldots$ & $9^{\mathrm{h}} 36^{\prime}$ \\
\hline 85 & $\ldots$ & $14^{b} 4^{\prime}$ & $\ldots$ & $9^{\mathrm{h}} 56^{\prime}$ \\
\hline 90 & $\ldots$ & $13^{\mathrm{h}} \mathbf{4} 7^{\prime}$ & $\ldots$ & $10^{h} 13^{\prime}$ \\
\hline 95 & $\ldots$ & $13^{\text {h}} 33^{\prime}$ & ... & $10^{\mathrm{h}} 27^{\prime}$ \\
\hline 100 & $\ldots$ & $13^{\text {h }} 20^{\prime}$ & $\ldots$ & $10^{h} 40^{\prime}$ \\
\hline 105 & $\ldots$ & $13^{\text {h }} 7^{\prime}$ & ... & $10^{\mathrm{h}} 53^{\prime}$ \\
\hline 110 & $\ldots$ & $13^{h} 1^{\prime}$ & ... & $10^{\mathrm{h}} 59^{\prime}$ \\
\hline 115 & ... & $12^{\mathrm{h}} 54^{\prime}$ & ... & $11^{\mathrm{h}} 6^{\prime}$ \\
\hline 120 & ... & $12^{\mathrm{h}} 50^{\prime}$ & ... & $11^{\mathrm{h}} 10^{\prime}$ \\
\hline 125 & ... & $12^{\mathrm{h}} 48^{\prime}$ & ... & $11^{\mathrm{h}} 12^{\prime}$ \\
\hline$* 130$ & $\ldots$ & $12^{\mathrm{h}} \mathbf{4} 7^{\prime}$ & ... & $11^{\text {h }} 13^{\prime}$ \\
\hline 135 & $\ldots$ & $12^{\mathrm{h}} 49^{\prime}$ & $\ldots$ & $11^{\mathrm{h}} 11^{\prime}$ \\
\hline 140 & $\ldots$ & $12^{\mathrm{h}} 53^{\prime}$ & $\ldots$ & $11^{\mathrm{h}} 7^{\prime}$ \\
\hline 145 & $\ldots$ & $12^{\mathrm{h}} 58^{\prime}$ & $\ldots$ & $11^{\mathrm{h}} 2^{\prime}$ \\
\hline 150 & $\ldots$ & $13^{\mathrm{h}} 6^{\prime}$ & $\ldots$ & $10^{\mathrm{h}} 54^{\prime}$ \\
\hline
\end{tabular}

It would be better at this juncture to mention that these facts can be considered in relation with the heart-sounds, and that certain departures from the normal condition may 
be roughly estimated by the stethoscope. The first sound of the heart indicates commencement of ventricular systole, the second sound follows immediately after cessation of ventricular contraction, a slight pressure forward of the descending line probably being due to shock of closure of the semilunar valves. Now, in great aberrations from the relative length of systolic and diastolic interval the rhythm of the heart-sounds is different from that in health. Small deviations are of course only made apparent by measurement of a skilfully-taken cardiographic tracing, and could not possibly be detected by the ear.

To consider the healthy rhythm. Where the total cardiac revolution occupies $1 \cdot 0^{\prime \prime}$ the ventricular systole, or (speaking roughly for the purpose I have in hand) the interval between the first and second sounds of the heart occupies '3345", or almost exactly one third of the total cardiac revolution :

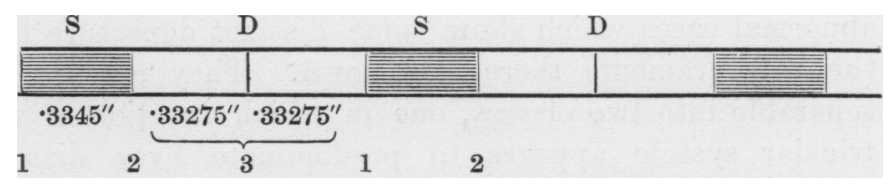

On auscultation we can clearly distinguish the rhythm of the sounds in such a normal heart, and could distinctly count "three" in the middle of the pause; the rhythmical recurrence to "one" falling on the first sound of the next revolution. The sounds of a healthy heart beating rapidly, say at 120 , do not take the same rhythm. Normally, for a pulse-rate of 120 the time interval between the first and second sounds is '2325", that of diastolic rest is ' $2675^{\prime \prime}$, the difference in time in favour of diastole being only $3 \frac{1}{2}$ hundredths of a second, which would be inappreciable by the ear. We may therefore in this case assume that the duration of systole and diastole are equal, and that the first and second sounds of the heart would fall thus :

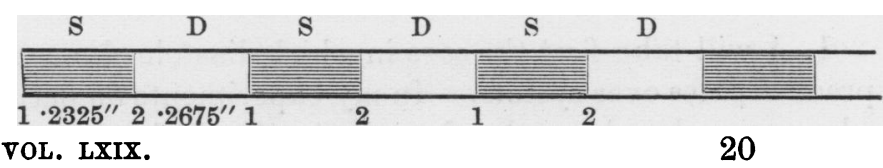


It is to be observed from these facts that in the healthy heart the interval is always less between the first and second sounds than it is between the second and first sounds, even for high pulse-rates ; and that therefore auscultation of the healthy heart in no case reveals any departure from the utmost regularity of interval between the sounds, except in the increased interval between the second and first sounds, i.e. in diastolic interval, when the pulse rate is low. I have formulated this into a law, stated thus :

In a healthy heart the time interval between the first and second sounds is never less than one third, nor exceeds one half, of the time occupied by an entire cardiac revolution.

In disease obvious discrepancies of rhythm will soon become noticeable to those who make a stethoscopic examination, bearing in mind the law I have enunciated.

To return to my table. I have to indicate the kinds of abnormal cases which show some distinct departure from the measurements there laid down. They are broadly separable into two classes, one in which duration of ventricular systole appears to predominate over diastolic interval, and another in which diastolic interval appears to predominate unduly over duration of ventricular systole. These, again, would each have to be divided, did knowledge permit of it, Class 1 into cases in which the duration of ventricular systole is actually increased, and cases in which the duration of ventricular systole is apparently increased owing to shortening of diastole; Class 2 into cases in which the ventricular systole is actually shortened, and cases in which the shortening is apparent owing to lengthening of diastole.

\section{Abnormadities.}

1. I will take first the case in which diastole abnormally predominates over systole. In my experiments on patients who were placed in the dry air (or Turkish) bath, at a 
temperature of about $140^{\circ} \mathrm{F}$., and sometimes kept there for an hour or more, I found that the duration of ventricular systole occupied less time than it did in the same patient at the same pulse-rate when the tracing was taken under normal conditions. I at first attributed this to the lessened blood-pressure, owing to the dilatation of the capillaries of the skin, thinking $a$ priori that if the heart had less obstruction to overcome the systole of the heart would probably be less prolonged. If patients were brought out of the bath and subjected to a cold douche the systole immediately lengthened, with a reduction of the pulse frequency it is true, but regaining the normal duration for the pulse-rate in question.

This I attributed to increased blood-pressure, owing to the contraction of the capillaries and tonic action on the heart by reflex shock.

2.

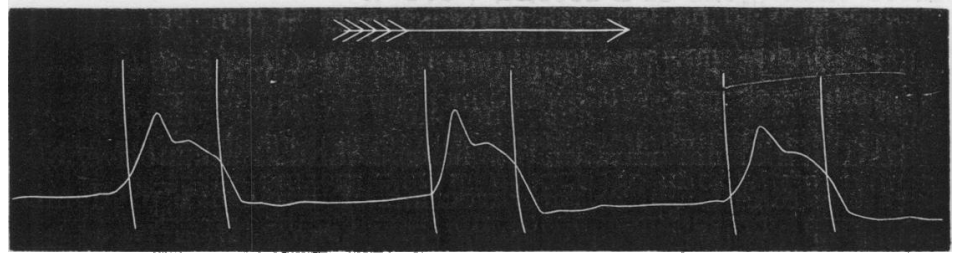

Faintness in Turkish bath. Systole $\cdot 210^{\prime \prime}$. Diastole •450. Pulse-rate 90.

I induced two young men to submit themselves to simultaneous compression of the large vessels, including the abdominal aorta, but without succeeding in increasing the duration of systole. I also took digitalis for two days, and have subjected a willing patient for three days to the influence of digitalis in large doses, and although I succeeded in decidedly reducing the frequency of contraction I did not increase the duration of systole, allowing for the reduced pulse-rate.

It then occurred to me that possibly the temperature of the blood might reduce the duration of systole, as I had an idea in great simplicity that the contraction of a 
muscle in a warm chamber was more sudden and sooner over than is the case when the muscle is in a cooler medium; and, with this view, I took the temperature of the body after long subjection to the bath, and found that I often got a temperature of about $102^{\circ} \mathrm{F}$. This again is not to be made much of, since in the case of fevers the systole of the heart is not necessarily shortened in time; and I do not attach much importance to it.

In cases of great exhaustion and prostration I have found the duration of systole very markedly shortened, and my attention was turned to the condition of the patients I had subjected to the Turkish bath. I found that this shortening was most marked in those cases in which the patient was feeling very faint, though it was often unaccompanied with any complaint of faintness. When fainting is imminent, however, it is very marked; and I have found the duration of systole less than normal by more than $\frac{7}{100}$ ths of a second $\left(\cdot 073^{\prime \prime}\right)$.

It was pointed out to me by Dr. Broadbent, to whom I am indebted for many suggestions and much information, that the cases in which the most marked discrepancy from the normal rhythm of heart-sounds was noticeable by the stethoscope, in the direction of excessive predominance of diastolic over systolic time, were those in which dilatation of the heart was present. Although I do not think this could be demonstrated in every case of dilatation, I certainly have noticed many cases in which, with regular rhythm, the diastolic pause is abnormally long, the systole being short, sudden, and feeble. These cases will improve under treatment, that is to say, as the patient improves in health the rhythm (which is not necessarily irregular) approximates more and more to the normal rhythm. For the first suggestion of these facts, as regards dilatation, I am wholly indebted to Dr. Broadbent, who assured me that under iron and strychnine patients would improve in this particular respect, as in others; and, as was to be expected, I have found Dr. Broadbent's observations to be entirely correct. On the 
whole I am inclined to think, on consideration of the many cases of comparatively short systole which I have studied, that this condition is not to be attributed to lessened blood-pressure, nor in fever to increased temperature of the blood, but to be immediately due to weakness of the heart muscle and exhausted or defective innervation.

I am strengthened in this conclusion by my observation of the action of nitrite of amyl, the administration of which is attended by dilatation of peripheral vessels and great fall in blood-pressure. The effect on the heart is very well and prettily shown in a tracing taken by myself from my own heart. The height the lever attains is

3.

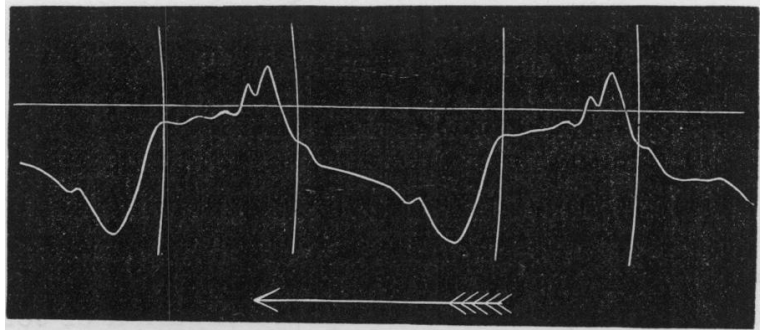

Normax. Systole $3220^{\prime \prime}$. Diastole '4715". Pulse-rate 75. Height of initial ascent of lever $8 \mathrm{~mm}$.

reduced, first to $7 \mathrm{~mm}$., then to $3 \mathrm{~mm}$; the heart is greatly accelerated (from 75 to 116 beats per minute), but it will be observed that the duration of systole is not

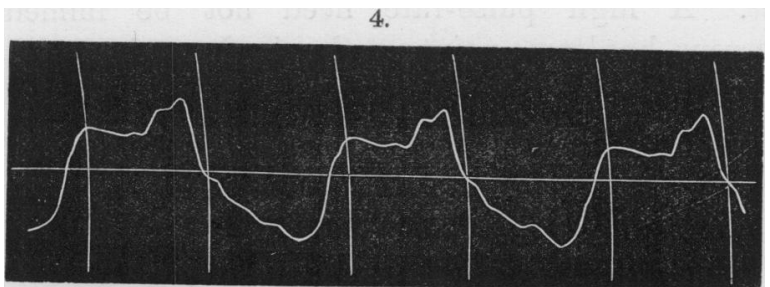

Nitritz OF AMYL (slight effect). S. $\cdot 2760^{\prime \prime}$. D. $\cdot 3335^{\prime \prime}$. Pulse-rate 98. Height $7 \mathrm{~mm}$. 
lessened out of proportion to the increased rapidity of the pulse, but is rather increased in duration.

As I have mentioned the action of nitrite of amyl I ought to say that under its influence the heart tracing sometimes exhibits the phenomenon of dicrotism. There

5.

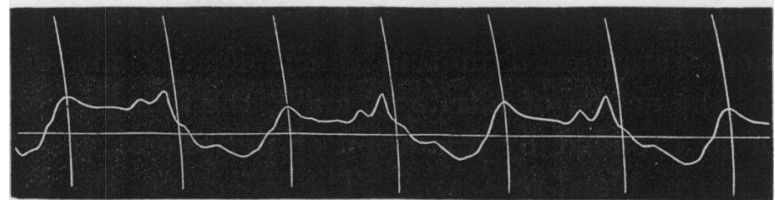

NITRITE OF AMYI (full effect). S. "2645". D. '2530". Pulse-rate 116. Height $3 \mathrm{~mm}$.

appears to be a curve or dip during systole in the tracing taken from myself which may possibly mean oncoming dicrotism. I would discuss the question of dicrotism, but the limits of my paper are short and I must confine myself strictly to the matter in hand, viz. the relations between systolic and diastolic interval.

2. To pass to the other class of cases; those in which there is relative excess of systole over diastole. How much this may be due, on the one side, to shortening of diastolic interval, on the other to prolongation of contraction, one cannot say. Using the word fancy to express my lack of scientific proof, I fancy that in most cases it is the shortening of diastolic interval which gives apparent length to the systole. The whole of this subject is of great interest and importance, especially as regards the administration of drugs with a view to their remedial effect. A high pulse-rate need not be immediately dangerous, but let me point out that in these abnormal cases, when systole greatly predominates over diastole, one of the chief things to apprehend is the exhaustion of the patient's cardiac strength. In some cases, in which on auscultation the second sound immediately precedes the first sound (the interval between the first and second sound appearing to be perhaps twice as long as that between the second and first), the heart may be doing forty-eight more 
hours' work in the week than it should be doing. In these cases to attempt to slow the heart by prolonging systole might be a grave error. I can give a very interesting, while very short, account of a patient which will bring out these points strongly.

F. J-, a boy æt. 6, was admitted under my care into the Royal Hospital for Women and Children, on March 26th, 1885. Three months previously he had had pains in the knees and ankles, which slightly swelled. He said he was then in bed a fortnight and suffered from sweating. He remained well till a fortnight before admission, since which time he had had pains in the legs and wrists and could not sleep. He looked pale and thin. There was no appreciable swelling of wrists. Temperature $100 \cdot 8^{\circ}$. The pulse-rate was nearly 150 in the minute. On auscultation a slight systolic murmur was heard at the apex of the heart extending into the axilla.

The sounds of the heart, though rhythmical, did not follow the normal rhythm, which would give an equal interval between both first and second and second and first sounds. The rhythm was altered in such a way that, on listening with the stethoscope, the first sound followed close upon the second sound, the interval between the first and second being about twice as long as that between the second and first.

Two days after, on March 27th, I obtained a tracing from the heart, which I here publish :
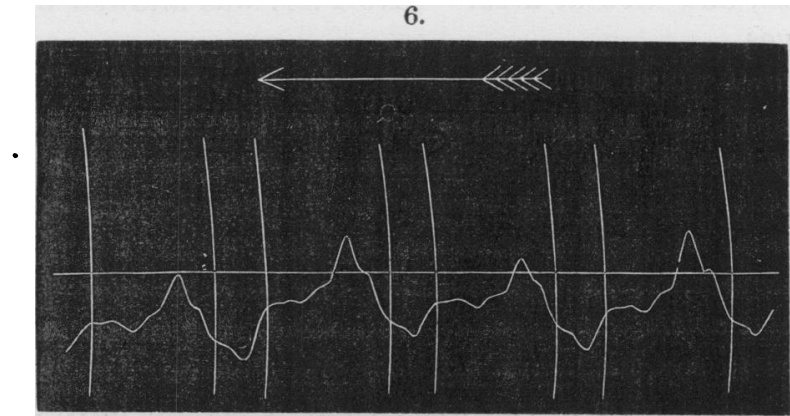

F. J-, æt. 6. Systole '2990". Diastole -1035". Pulse-rate 149 . 
The time occupied by diastole was so inadequate for rest, and the period of labour was so prolonged in proportion, that, on merely looking at the tracing, I observed to the house surgeon that unless some alteration in the character of the tracing took place the strength of the heart must inevitably fail and the boy would gradually die. I saw him twice afterwards. The state of the heart remained the same. He took digitalis and citrate of potash. Subsequently, on April 1st, complaining of pains in the joints, he took salicylate of soda, which was stopped as he could not retain it. I feared the digitalis harmed him and gave him no more, but tried to support his strength. My treatment was more miserably inefficient than I hope it would be in a future case. The temperature only twice reached $101^{\circ}$, was mostly about $100^{\circ}$, and gradually fell to normal during the 28th, 29th, and 30th, though it rose very slightly during the next few days. There was no albumen in the urine. On my next visit (April 4) the following notes were read to me by the house surgeon :

"Patient began to sink this morning gradually, lasting over many hours. No convulsions, no pain, no insensibility. At 1 p.m. he was almost pulseless and brandy was given. He was very restless for half an hour and said he could not breathe. Was then quiet for a short time, after which he again suffered from dyspnœa. He was again quiet till 2.30 , when he again became very restless, and died at 2.40." No P.M. was allowed by the relatives.

Now, I would call attention briefly to the tracing. The period of rest at pulse-rate 149 should be thirteen out of twenty-four hours. The period of rest in my patient was 6 h. 10". During the week of 168 hours during which he was under my care he had had only forty-three hours' ventricular rest, instead of the ninety-one hours he should have obtained at the same pulse-rate had all else been normal. That is to say, his heart had been doing exactly forty-eight hours' more work in the week than it should have done. 
I regret now that I did not largely increase his digitalis to slow the pulse, or administer aconite, the action of which, however, I have not yet worked out.

Digrtalis.-Digitalis I have since investigated cardiographically, and find, contrary to what I had been led to expect, that it does not lengthen the duration of systole of the ventricles. In the accompanying tracing its action is well seen. The heart was not beating quite regularly before the administration of the drug, the cardiac revolutions are reduced in frequency per minute, the action is regulated, the initial shock seems not to be so great, and there is a gradual rise to the end of systole, which well persists. Thus both systole and diastole are lengthened, the lower pulse-rate itself affording the heart more rest, as can be immediately seen by referring to my second table. Digitalis seems to affect a regulatory nervous apparatus ; its salutary effect is best seen in the irregular heart of mitral disease ; and I believe it deserves the name of a heart tonic in that respect, and not so much in the

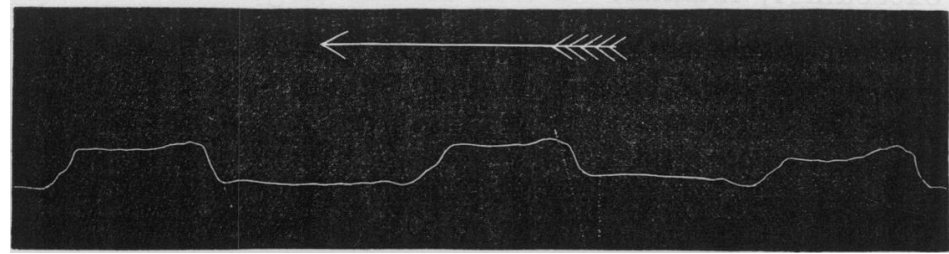

IBREgULAR HEART. Ventricular systole $\cdot 3335^{\prime \prime}$ to $\cdot 3105^{\prime \prime}$. Diastole $46000^{\prime \prime}$ to $\cdot 7360^{\prime \prime}$ (varying interval -2760'). Average pulse-rate 67.

8.

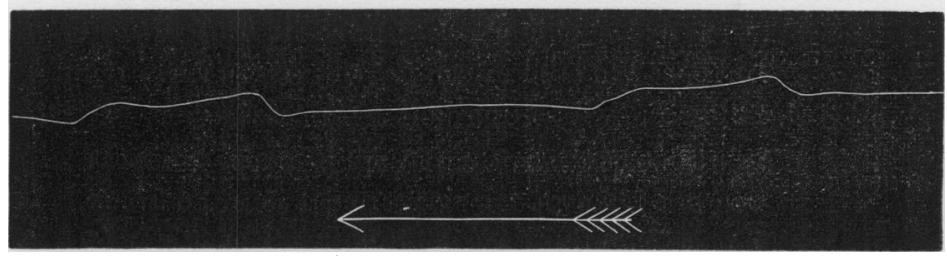

Efrict of Digitalis on same Heart (170 minims of the tincture were taken in forty-eight hours). Ventricular systole (constant) $\cdot 3680^{\prime \prime}$. Diastole $\cdot 7130^{\prime \prime}$ to $\cdot 8740^{\prime \prime}$ (varying interval $\cdot 1610^{\prime \prime}$ ). Pulse-rate 50. 
sense of increasing the force and duration of ventricular contraction. I have succeeded by its administration in even making the heart irregular as if by exhaustion of the said regulatory centre.

Convaluaria is a heart tonic which probably differs from digitalis in not only slowing the heart, but in actually lengthening the duration of systole of the ventricle. The tracing which I give of the action of

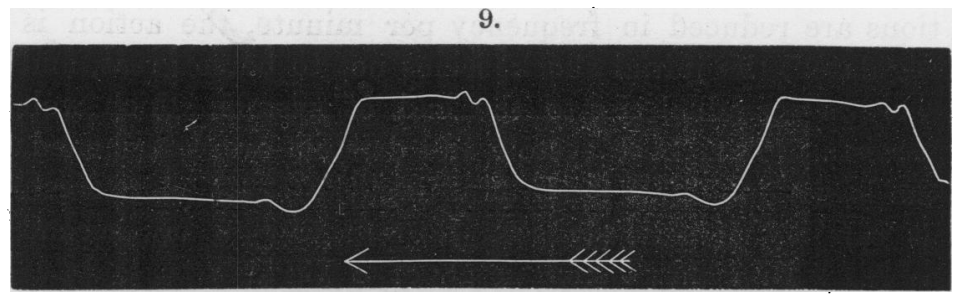

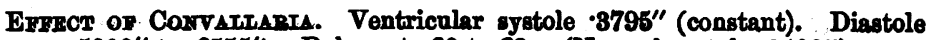
-5900" to '6555". Pulse-rate 60 to 68. (Normal systole $3400^{\prime \prime}$ ).

convallaria is taken from my own heart, with which I am exceedingly familiar. I took several large doses of the tincture of convallaria in this experiment, thirty to forty minims every half hour for two hours in the morning. I had diarrhcea and a feeling of præcordial constriction in the afternoon, with some giddiness. It will be seen at once, on comparison with my table No. 1 , that there is a very perceptible increase in the duration or persistence of ventricular contraction. I have no time to discuss the respective therapentic advantages of these drugs.

I shall hope to make the action of other drugs on the human heart the subject of future papers.

Besides bringing forward my results I am anxious to popularise the cardiograph. It is an instrument which every physician might have in his consulting room; it is very easy to apply and I have no doubt that a good instrument maker, if he put himself to it, could turn out thoroughly convenient and accurate instruments of this nature at a reasonable price, if there were a demand for 
them. Though I do not like to say my table of measurements will require no alterations whatever, $I$ yet believe that it will, for practical purposes, stand any reasonable test. This, the most laborious part of the work, the establishing a basis to work by, has now, to my mind, been done; and I should welcome with great pleasure other workers into a field wherein I feel somewhat solitary.

(For report of the discussion on this paper, see 'Proceedings of the Royal Medical and Chirurgical Society,' New Series, vol. ii, p. 78.) 